\title{
Comparison Microlaryngeal Surgery with Carbon Dioxide Laser in Management of Benign and Premalignant Lesions of Larynx
}

\author{
Rachana Prasad, ${ }^{1}$ Ajay Mallick ${ }^{2}$
}

\begin{abstract}
Introduction
Dysphonia is caused by voice misuse and various environmental factors. It is manifested as varied pathological lesions of the vocal cords. Surgical excision of these lesions is mainly by conventional cold steel or laser assisted microsurgical techniques. Both modalities have seen extensive advancements and refinement in technologies in the recent past. In this study we have compared the microdissection microlaryngeal treatment and microspot superpulsed beam carbon dioxide (CO2) laser assisted surgical techniques for the management of benign and precancerous lesions of the vocal cords.

Material and Methods

A total of 36 cases of benign lesions of vocal cord, were divided randomly to undergo surgery either by microdissection or $\mathrm{CO} 2$ laser assisted techniques. The groups were assessed through vocal cord morphological observation and subjective voice assessment parameters GRBAS score and VHIIO index.

$\underline{\text { Results }}$

Peroperative bleeding was observed to be significantly reduced in the laser excision group. However, operating time was significantly increased in this group. Patients recovered remarkably well following both the techniques as denoted by voice parameters. No difference was observed in duration of hospital stay.

Conclusion

Both surgical techniques give satisfactory results in their management of benign and precancerous lesions of the vocal cords. Both techniques have their advantages and disadvantages. After a learning curve, laser surgery with its precision and cleaner surgical fields will be more effective in the management of such cases.

$\underline{\text { Keywords }}$

Lasers; Microdissection; Vocal Cords
\end{abstract}

$\underline{\text { ABSTRACT }}$

$\mathrm{D}$ ysphonia affects people of all ages, gender and social structure. It is caused by a variety of voice disorders. The reasons are multifactorial usually due to improper voice use and environmental factors. The condition is distressing to the individual and needs accurate diagnosis and timely institution of appropriate therapeutic intervention. 1

Based on stroboscopic and scanning electron microscopy evidence, the vocal fold is divided into five layers. Only the mucosal epithelial and Reinke's space vibrate to produce a tone. The treatment of voice disorders hence requires minimally invasive dissection in these layers for an effective return to proper sound function and voice.
Two types of microsurgical techniques are widely practiced, the conventional cold steel laryngeal microsurgery and the laryngeal laser micro-surgery. The role of carbon dioxide (CO2) laser in early laryngeal carcinoma treatment is well documented. ${ }^{2}$ However, treatment of benign laryngeal diseases such as vocal

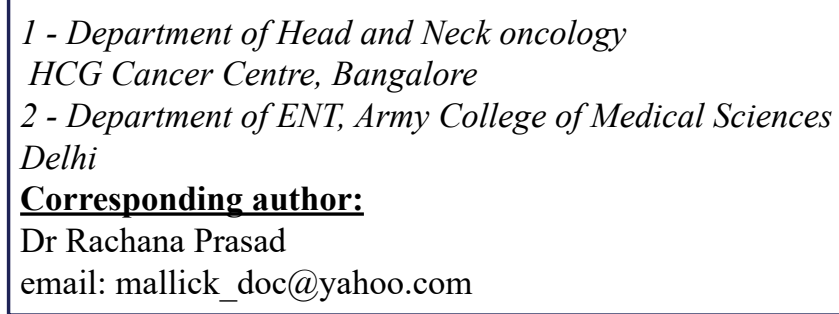


cord polyps, vocal nodules and precancerous lesions such as vocal cord leukoplakia, remain controversial. ${ }^{3,4}$

Advancements have been made in both techniques to redefine and improve outcomes of surgery of lesions of the vocal cords. Microsurgery of the vocal cords has become more precise with the advent of the microdissection and microflap techniques. Early use of $\mathrm{CO} 2$ lasers induced greater thermal damage which affected the healing and outcomes of the surgery. The introduction of the microspot mode has refined the mode of delivery and depth of delivery of the laser to the tissue. ${ }^{5}$

In the present study, the newer advancement in both techniques, have been compared in the management of benign and precancerous lesions of the vocal cord. The groups were assessed through vocal cord morphological observation by fibreoptic laryngoscopy and by comparative analysis of subjective voice assessment parameters using GRBAS and VHI index scores.

\section{Materials and Methods}

This study was conducted at the Department of Otolaryngology-Head and Neck Surgery, at a tertiary care center at Kolkata between 2014-2016 after ethical clearance.

Fifty cases of vocal cord lesions as confirmed by fibreoptic laryngoscopy were included in the study. Cases which on histopathology were diagnosed to be malignant and cases which could not be followed up for 3 months postoperatively were excluded from the study. After excluding such cases, a total of 36 cases were evaluated and studied on the following parameters:

a. Visual analysis on fibreoptic laryngoscopy

b. Voice analysis -VHI 10 and GRBAS indices

c. Time of surgery analysis

d. Peroperative bleeding

The results were analysed using Statistical Package for Social Sciences (SPSS) version 20. Fischer Exact test was used to find the significance of study parameters for the categorical data and the Student $t$ test was used for the data variables in the continuous scale. The Student unpaired $t$ test was use to compare the data between the two groups and the Student paired t test for comparison between the preoperative and postoperative results within the same group. In all the tests the level of significance was taken as $p \leq 0.05$. Written and informed consent was taken prior to surgery for each patient. Preoperative assessment was done with fibreoptic laryngoscopy and subjective analysis of voice.

Patients were then assigned to the following two groups by the total consecutive sampling method:

a. Microdissection group

b. Laser excision group

All the patients underwent surgery under general anaesthesia. Laser safe endotracheal tube were used for intubation in patients of the laser excision group.

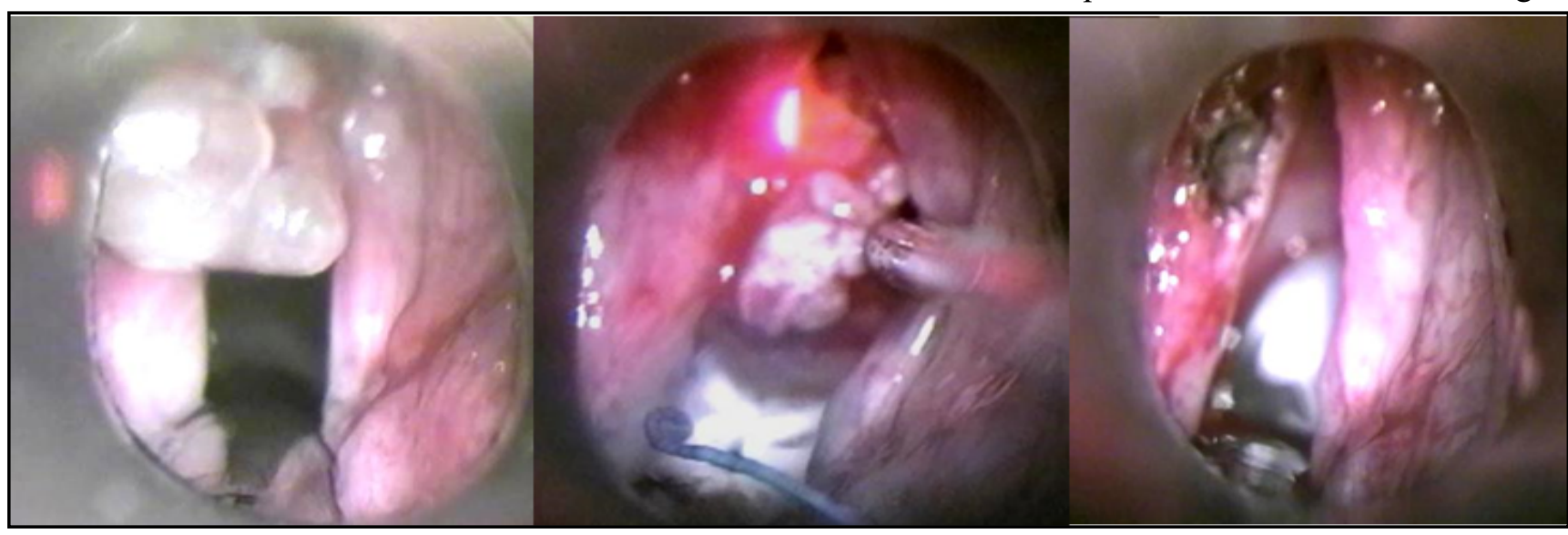

Fig.1. Preoperative, intraoperative and immediate postoperative view of laser assisted microlaryngeal surgery 
Operating microscope at 400-mm focal length through a suspension laryngoscope was used for all surgeries.

In microdissection group, excision of small vocal nodules and pedunculated polyps was done by hydrodissection using normal saline followed by excision using microforceps and microscissors with preservation of the underlying middle and deep layers of the lamina propria and muscles.For larger nodules and diffuse polyps, the microflap technique was employed.

In laser excision group, institutional laser precautions and safety procedures were strictly followed. Laser microsurgery was performed using microspot $\mathrm{CO} 2$ surgical laser. Firstly, hydrodissection was done with normal saline and then, pledgets soaked in normal saline placed over the surrounding areas to prevent accidental injury to surrounding structures. The laser beam was focused to smallest spot size $(0.2-0.25 \mathrm{micrometre})$ for excision and set at 0.05 seconds repeat superpulse mode after holding the lesion with laryngeal forceps (Fig 1).

Postoperative assessment of patients by fibreoptic laryngoscopy after 1 week and after 3 months, were classified as "Excellent result"- voice returned to normal and vocal cords appeared normal, "Good result" - mild hoarseness present or lesion did not disappear completely and "Poor result"- no change in quality of voice. Assessment of all patients was also done by subjective methods of voice assessment (GRBAS score, VHI 10 index) after 3 months for comparative analysis.

\section{Results}

A total of 36 cases underwent surgery for benign lesions and precancerous of vocal cord out of which 14 (38.89\%) were male and 22 (61.11\%) were female. The patients were between the age range of 20 years to 60 years and mean age was $39.99 \pm 9.18$ yrs. The distribution of patients in the microdissection group according to the pathology was vocal cord polyp (44.4\%), vocal cord nodules $(38.9 \%)$, vocal cord cyst $(5.5 \%)$ and keratosis of vocal cord (11.1\%).

Similarly, patients included in laser excision group were vocal cord polyp (38.9\%), vocal cord nodule $(44.4 \%)$, vocal cord cyst $(11.1 \%)$ and leukoplakia of vocal cord $(5.6 \%)$. (Table I).

\section{Voice outcomes}

In our series, patients recovered remarkably well subjectively in both the groups.

Microdissection group

- Mean GRBAS score (15.92preop. to 7.54 postop.)

TABLE I: Preoperative assessment of cases

\begin{tabular}{|c|c|c|}
\hline AGE DISTRIBUTION (YRS) & MICRODISSECTION & LASER EXCISION GROUP \\
\hline $21-30$ & 4 & 5 \\
\hline $31-40$ & 5 & 4 \\
\hline $41-50$ & 8 & 6 \\
\hline$>50$ & 1 & 3 \\
\hline Mean age & $38.13 \pm 10.59$ & $41.64 \pm 7.95 y r s$ \\
\hline PATHOLOGICAL DISTRIBUTION & MICRODISSECTION & LASER EXCISION GROUP \\
\hline Gocal cord polyp & 8 & $\mathbf{7}$ \\
\hline Vocal cord nodules & 7 & 2 \\
\hline Vocal cord cyst & 1 & 1 \\
\hline Leukoplakia of vocal cord & 2 & \\
\hline
\end{tabular}


- $\quad$ Mean VHI 10 score (8.17 preop. to 2.72 postop.)

Laser assisted surgery

- Mean GRBAS score (16.14 preop. to 7.28 postop.)

- Mean VHI 10 score (8.06 preop. to 2.89 postop.)

\section{Time analysis}

The total intubation time in the microdissection group was 70.35 minutes while in the laser assisted group it was 77.06 minutes. The total hospital stay in the microdissection group was 46.76 hours and in the laser assisted group was 47.65 hours. In our study, operating time was significantly increased in the laser assisted group ( $\mathrm{p}$ value $<0.05$ ). No difference was, however, observed in duration of hospital stay.

\section{Peroperative bleeding}

In our study, peroperative bleeding was significantly reduced in the laser assisted group ( $\mathrm{p}$ value of 0.0015 was obtained).

The results are summarized in Table 2 .

\section{Discussion}

Benign and precancerous, lesions of the vocal folds, encompass changes in epithelium (vocal nodules, leukoplakia, hyperkeratosis, acanthosis, dysplasia, etc.), exudative changes in the Reinke's space (vocal cord polyps, Reinke's edema), granulomas (contact granuloma, intubation granuloma), scarring, and subepithelial lesions such as cysts. ${ }^{6-9}$

They are caused as a response to vocal trauma to the laryngeal mucosa by means such as excessive talking or coughing, use of inappropriate pitch and throat clearing. Vibration-induced elevations in capillary pressure have been hypothesized to induce vocal edema and nodules. ${ }^{10}$

The modern optimal treatment of benign and precancerous vocal fold lesions has primarily been a choice between microsurgical and laser surgical techniques. The properties of lasers which makes it beneficial in surgery are its monochromaticity (only one wavelength), coherence (wave travels in phase and in one direction) and concentrated direction of the beam. ${ }^{11}$ However, lasers cause thermal tissue damage which may cause excessive scarring. Factors which cause the damage is dependent upon, the tissue absorption coefficient, the wavelength of the laser, the duration of delivery, and the thermal relaxation time ie. time required for the tissue to lose $50 \%$ of the heat absorbed. ${ }^{12}$

Microsurgical techniques have become more refined and precise with more modern instruments and techniques such as micro dissection and mucosal flap techniques. In the past, lasers proved to be less effective than microsurgery at treating most benign lesions due to high thermal burns and laser surgery related complications such as fire in the endotracheal tube. However, with advancements in the $\mathrm{CO} 2$ laser technology such as the microspot technique and preventive protective precautions, surgery with lasers have become safer, precise and associated with minimal bleeding. Continuing recent advances in both surgical techniques ensure that the outcomes of surgery have become more effective.

In our case series of 36 cases, patients recovered remarkably well in both the groups. Voice assessment by the VHI and GRBAS in both groups showed improvement in post-operative results. There was no statistical difference in the results in voice assessment after surgery in both groups. With more experience in recent times in the use of laser, surgical and voice results have improved as compared to earlier studies. ${ }^{12}$

With the development of the microspot $\mathrm{CO} 2$ laser with a spot size of $250 \mu \mathrm{m}$ or less, the potential risk to the deeper tissues has been minimized due to time available for tissue cooling between the laser pulses. Furthermore, superpulse modes have allowed for the ability to provide higher power while minimizing thermal damage.

Setting up the laser surgical unit as well as the procedure is time consuming. In our study, operating time was significantly increased in the laser assisted group as compared to the microdissection technique ( $p$ value of $<0.05$ ). The postoperative recovery and morbidity in both groups was not statistically significant. No difference was hence observed in duration of postoperative hospital stay. In the study conducted by Benninger et al, there were no differences in intubation (surgical) time, recovery room time, or total time of 
TABLE II: Post operative results

\begin{tabular}{|c|c|c|c|c|}
\hline 1 & FACTOR EVALUATED & $\begin{array}{l}\text { MICRODISSECTION } \\
\text { GROUP }\end{array}$ & $\begin{array}{l}\text { LASER EXCISION } \\
\text { GROUP }\end{array}$ & $\begin{array}{c}\text { P VALUE } \\
\text { (BETWEEN } \\
\text { THE } 2 \\
\text { GROUPS) }\end{array}$ \\
\hline \multirow[t]{4}{*}{$1 \mathbf{a}$} & $\begin{array}{c}\text { Videolaryngoscopic } \\
\text { appearance (after } 1 \text { week) }\end{array}$ & & & \\
\hline & Excellent & 13 & 16 & \\
\hline & Good & 5 & 2 & \\
\hline & Poor & - & - & \\
\hline \multirow[t]{4}{*}{$1 \mathrm{~b}$} & $\begin{array}{c}\text { Videolaryngoscopic } \\
\text { appearance (after 3months) }\end{array}$ & & & \\
\hline & Excellent & 16 & 15 & \\
\hline & Good & 2 & 3 & \\
\hline & Poor & - & - & \\
\hline 2 & \multicolumn{4}{|c|}{ VOICE OUTCOMES } \\
\hline \multirow[t]{4}{*}{$2 \mathbf{a}$} & VHI 10 indices & & & \\
\hline & Preoperative VHI10 index & $8.17 \pm 0.69$ & $8.06 \pm 0.78$ & \\
\hline & Postoperative VHI10 index & $2.72 \pm 0.628$ & $2.89 \pm 0.66$ & \\
\hline & p value & $\begin{array}{c}\text { p value of } 0.0001 \\
\text { (between pre and post op } \\
\text { observations) }\end{array}$ & $\begin{array}{l}\text { p value of } 0.0001 \\
\text { (between pre and post } \\
\text { op observations) }\end{array}$ & 0.0001 \\
\hline \multirow[t]{4}{*}{$2 \mathbf{b}$} & GRBAS score & & & \\
\hline & Mean GRBAS score & $\begin{array}{ll}\text { Preoperative } & -15.92\end{array}$ & Preoperative $-\mathbf{1 6 . 1 4}$ & \multirow{3}{*}{0.0001} \\
\hline & & Postoperative $\quad-7.54$ & Postoperative -7.28 & \\
\hline & & $p$ value- 0.0001 & p value- 0.0001 & \\
\hline 3 & $\begin{array}{c}\text { TIME ANALYSIS (IN } \\
\text { HOURS) }\end{array}$ & MEAN/SD & MEAN/SD & \\
\hline $\mathbf{3 a}$ & $\begin{array}{c}\text { Duration of operation (total } \\
\text { intubation time) }\end{array}$ & $70.35 / 1.71$ & $47.65 / 5.72$ & 0.0072 \\
\hline $\mathbf{3 b}$ & Duration of hospital stay & $46.76 / 4.83$ & $3.06 / 0.55$ & 0.6173 \\
\hline 4 & \multicolumn{4}{|c|}{ PER OPERATIVE BLEEDING } \\
\hline $4 a$ & $\begin{array}{c}\text { Per operative Bleeding (in } \\
\text { ml) }\end{array}$ & $3.88 / 0.76$ & $3.04 / 0.52$ & 0.0015 \\
\hline
\end{tabular}


stay. ${ }^{5}$

Peroperative bleeding was significantly higher in the microdissection group as compared to the laser assisted group ( $p$ value of 0.0015 ) especially in the precancerous cases. The properties of lasers suitable and beneficial in obtaining haemostasis in surgery are its monochromaticity (single wavelength), coherence (travels in phase and in one direction) and concentrated direction of the beam. Our findings were similar to study by Mizuta et al, who showed that use of $\mathrm{CO} 2$ laser was particularly indicated for vascular lesions of the vocal cords as it helped to achieve better haemostasis. ${ }^{13}$

However, lasers can cause thermal tissue damage. The tissue absorption coefficient, wavelength, duration of delivery and the thermal relaxation time (time required for the tissue to lose $50 \%$ of the heat absorbed), all affect the degree of thermal penetration. ${ }^{14}$ Laser burns have been reported due to fire within the endotracheal tube. The use of laser endotracheal tubes and saline soaked gauze around the tube prevented such incidents. ${ }^{15,16} \mathrm{In}$ our study we incorporated similar precautions and did not have any such complications.

The microspot CO2 laser with a spot size of $250 \mu \mathrm{m}$ or less prevents collateral damage. The potential thermal risk to the deeper tissues is further minimized with the use of superpulse modes due to time available for tissue cooling between the laser pulses. Fewer complications, side-effects and better postoperative voice quality have been reported in the treatment of benign lesions of vocal cords with lasers due to their accuracy, need of minimal tissue manipulation and unobstructed vision of the operative site with minimal surrounding tissue damage. ${ }^{12,17}$ However, we feel that the results are largely technique-dependent. The surgeons experience and skills has a major role to play in the results of laser surgery. In our study, after a learning curve, the ease of surgery and results obtained improved progressively.

\section{Conclusion}

Microsurgical dissection and lasers are the surgical modalities of treatment for benign and pre malignant lesions of the vocal cords. We found both techniques to give satisfactory results in their management.
Though both techniques have their advantages and disadvantages, laser surgery, after a learning curve, will benefit for its precision and limited need for tissue handling in the management of such cases. An analysis of larger series and results of more centers are required to refine the procedures for management of benign and pre malignant lesion of larynx.

\section{References}

1. Altman KW. Vocal fold masses. Otolaryngol Clin North Am. 2007 Oct; 40(5):1091-108

2. Shapshay SM, Wang Z, Rebeiz EE, et al. A combined endoscopic $\mathrm{Co} 2$ laser and external approach for treatment of glottic cancer involving the anterior commissure: an animal study. Laryngoscope 1996; 106:273-9

3. Sataloff RT, Spiegel JR, Hawkshaw M, et al. Laser surgery of the larynx: the case for caution. Ear Nose Throat J. 1992; 71:593-5

4. Devaiah AK, Shapshay SM, Desai U, et al. Surgical utility of a new carbon dioxide laser fiber: functional and histological study. Laryngoscope 2005; 115: 1463-8

5. Benninger MS. Microdissection or microspot $\mathrm{CO} 2$ laser for limited vocal fold benign lesions: a prospective randomized trial. Laryngoscope 2000; 110:1-17

6. Wuyts FL, De Bodt MS, Molenberghs G, et al. The dysphonia severity index: an objective measure of vocal quality based on a multiparameter approach. J Speech Lang Hearing Res. 2000; 43:769-809

7. DeJonckere PH, CrevierBuchman L, Marie JP, et al. European Research Group on the Larynx. Implementation of the European Laryngological Society (ELS) basic protocol for assessing voice treatment effect. Rev Laryngol Otol Rhinol (Bord). 2003; 124: $279-83$

8. Aaronson AE. Clinical voice disorders. Thieme, New York, 1990. p 45-6

9. Zeitels SM, Casiano RR, Gardner GM, Hogikyan ND, et al. Management of common voice problems: Com mittee report. Otolaryngol Head Neck Surg. 2002; 126: 333-48

10. Czerwonka L, Jiang JJ, Tao C. Vocal nodules and edema may be due to vibration-induced rises in capillary pressure. Laryngoscope 2008; 118(4): 748-52

11. Yan Yan, Olszewski AE, Hoffman MR, et al. Use of Lasers in Laryngeal Surgery. J Voice. 2010; 24(1): 102-9

12. Zhang Ya, Liang G, Na Sun, Linlin G, et al. Comparison of $\mathrm{CO} 2$ laser and conventional laryngomicrosurgery treatments of polyp and leukoplakia of the vocal fold. Int J Clin Exp Med. 2015; 8(10): 18265-74

13. Mizuta M, Hiwatashi N, Kobayashi T, Kaneko M, Tateya I, Hirano S. Comparison of vocal outcomes after angiolytic laser 
surgery and microflap surgery for vocal polyps. Auris Nasus Larynx 2015; 42 (6): 453-7

14. Fuller TA. Surgical Lasers: A Clinical Guide. New York: Macmillan; 1987. pp. 1-17

15. Shruti M. Shah, Manisha S. Kapadi, Darshna R. Shah, Heena R. Gajjar et al. Anaesthesia For Laser Surgery Of Larynx. Gujarat Medical Journal 2014; 69 (1):17-20
16. Xu W, Han D, Hou L, Zhang L, Yu Z, Huang Z. Voice function following $\mathrm{CO} 2$ laser microsurgery for precancerous and early-stage glottic carcinoma. Acta Oto-Laryngologica 2007; 127(6):637-41

17. Sethi A, Das A. Use of pulsed dye laser in the management of laryngeal lesions: The current perspective. J Laryngology and Voice. 2015; 5(2): 29-33. 